\title{
Achievement gap: Socioeconomic status affects reading development beyond language and cognition in children facing poverty
}

\author{
Dacian Dolean $^{\mathrm{a}, \mathrm{b}}$, Monica Melby-Lervåg ${ }^{\mathrm{c}}$, Ioana Tincas ${ }^{\mathrm{d}}$, Crina Damsa ${ }^{\mathrm{e}}$, Arne Lervåg ${ }^{\mathrm{e}, *}$

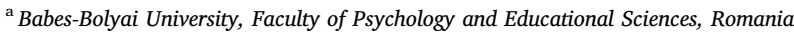 \\ ${ }^{\mathrm{b}}$ East Georgia State College, School of Humanities and Social Sciences, Georgia, USA \\ ${ }^{\mathrm{c}}$ Department of Special Needs Education, Faculty of Educational Sciences, University of Oslo, Norway \\ ${ }^{\mathrm{d}}$ Transylvanian Institute of Neuroscience, Romania \\ ${ }^{\mathrm{e}}$ Department of Education, Faculty of Educational Sciences, University of Oslo, Norway
}

\section{A R T I C L E I N F O}

\section{Keywords:}

Reading development

Socioeconomic status

Poverty

\begin{abstract}
A B S T R A C T
Learning to read efficiently is one of the main skills that children has to learn in school and is important in order to functioning well in modern society. Even if children's reading skills seem to be related to their socioeconomic status, only a few studies have examined how SES is related to the development of reading skills in children facing severe poverty. This study traced 322 Roma children facing severe poverty from 7 through 9 years and compared them with an unselected sample of 178 Romanian non-Roma children. The Roma children had both poorer initial reading and a slower growth of their reading skills. In contrast to previous studies, SES did explain growth in reading skills after controlling for other well-known cognitive and linguistic predictors of reading. Among the Roma children, the effects of SES on reading growth were partly mediated by school absence. Thus, interventions directed at Roma children facing severe poverty need to target both the quality of reading instruction and broader aspects of these children's lives.
\end{abstract}

\section{Introduction}

Education is a key factor in alleviating poverty and increasing the quality of life of children from vulnerable groups. However, the scarcity of rigorously conducted empirical studies that focus on severely disadvantaged groups is surprising (for a review, see Buckingham, Beaman \& Beaman-Wheldall, 2013). One such group facing extreme poverty across several European countries is the Roma population (Brüggemann, 2012; Fundamental Rights Agency, 2016; Kosko, 2012; Rat, 2005). The current study is conducted in Romania and examines the early reading development of disadvantaged children belonging to the Roma ethnic group. The study tracked the development of bilingual and monolingual Roma children during their first years of schooling while comparing it to the development of their non-Roma peers who live in the same communities. In addition to using more traditional linguistic and cognitive predictors of reading development, this study employs a set of indicators to measure aspects of socioeconomic background and examines how these aspects influence children's early reading development.

\subsection{Socioeconomic background and the prediction of early reading development}

A number of studies show moderate to high correlations between SES and reading and also that children in poverty are at a considerably lower level in literacy than their peers from higher SES backgrounds (Buckingham, Wheldall, \& Beaman-Wheldall, 2013; Hart \& Risley, 1995; Pan, Rowe, Singer, \& Snow, 2005; Sirin, 2005). Different variables are used as indicators of SES, but typically, SES is measured with factors such as income, educational level, employment and living conditions (Grusky, 2001). To disentangle the relationship between SES and reading, one must first examine whether a causal link between reading and SES is plausible. Therefore, it is crucial to clarify not only whether SES is associated with reading but also whether SES can explain development or growth in reading. This is crucial since a variable that can explain development can explain the actual change in a certain skill over time. Therefore, determining whether a variable can explain development has a better potential to disclose the mechanisms that underlie development rather than examining only whether a variable predicts the concurrent or initial variation.

Second, even if a variable can explain growth in reading, a third

\footnotetext{
${ }^{*}$ Corresponding author.

E-mail address: a.o.lervag@iped.uio.no (A. Lervåg).
} 
variable can also underlie this and consequently partially or fully explain the relationship. Therefore, determining whether growth is mediated by other factors is also crucial. Importantly, most previous longitudinal studies have not demonstrated a direct, potential causal relationship between SES and reading ability (for review see Buckingham et al., 2013). It is therefore often concluded that SES is primarily a proxy for additional variables that are more direct salient factors (Buckingham et al., 2013).

To unpack the relationship between SES and reading, it is important to take into account other variables that are well-known predictors of reading growth across different orthographies, such as letter knowledge, phoneme awareness and rapid naming (RAN) (Caravolas, Lervåg, Defior, Seidlová Málková, \& Hulme, 2013). Letter knowledge is important since one would not be able to link letters to sounds without first knowing the letters (Lervåg, Bråten, \& Hulme, 2009). Phoneme awareness is crucial since the ability to manipulate sounds is a prerequisite for linking letters to sounds (Lervåg et al., 2009). SES may be associated with reading because SES contributes to the development of letter knowledge and phonemic skills, which, in turn, contribute to the development of good reading skills. The relationship between RAN, i.e., the speed of naming pictures, numbers, etc., and reading is less obvious, but RAN has been hypothesized to influence the development of the visual word recognition system (Lervåg \& Hulme, 2009). However, since letter knowledge, phoneme awareness and RAN are critical for reading growth, it is important to examine whether these three predictors mediate the relationship between reading growth and SES, at least partially. This could point at the mechanisms working between SES and the development of reading skills.

School absenteeism is another variable that could potentially be a mediator of the relationship between SES and the growth of early reading skills. While school attendance is positively associated with academic achievement and reading performance (Gottfried, 2010), children raised in families with a low SES are particularly adversely affected by absenteeism (Morrisey, Hutchinson, \& Winsler, 2014; Ready, 2010). Accounting for school absenteeism is particularly important when measuring longitudinally the school performance of Roma children because studies shows that in general they have dramatic rates of school absenteeism, significantly higher than non-Roma in all surveyed European countries (Brüggemann, 2012; Fundamental Rights Agency, 2016). Thus, when investigating the relationship between SES and early reading development (particularly among Roma children), it seems pivotal to account for school attendance.

\subsection{Previous studies of SES and early reading development}

One of the few longitudinal studies that do incorporate some of the known predictors of beginning reading skills in addition to SES found that SES predicted early reading development in primary school, but in the earliest grades, the prediction was entirely accounted for by general intelligence, phoneme awareness and RAN (Hecht, Burgess, Torgesen, Wagner, \& Rashotte, 2000). These findings are fairly consistent with previous findings that showed that SES predicted the development of reading skills; however, the effects of SES were entirely accounted for by phonological awareness (Bowey, 1995; Raz \& Bryant, 1990). Also, one study showed that children with low SES had a steeper growth in reading in the lower grades compared with children with middle and high SES reflecting a compensatory developmental pattern in beginning reading skills. However, there were slower rates of growth for the lowSES children between third and eight grade (Kieffer, 2012).

When interpreting findings from these studies it is important to note that few of the children with low SES background actually lived in severe poverty. Generally, samples available for research are selected from countries with a higher degree of economic equity and, thereby have a restriction in range of SES (Henrich, Heine, \& Norenzayan, 2010). Therefore most previous studies commonly report that SES explains the variance in the initial status and correlates with early reading skills (for review, see Hoff, 2006). However, in these studies SES is rarely strong enough to explain growth in reading development over and above letter knowledge, phoneme awareness and RAN, and only appears to have an indirect influence on reading development. Still, in populations that include children from families living in severe poverty, thus representing a wider range of SES, this influence might differ.

If one takes a closer look at studies that have actually examined reading development of children living in severe poverty in Europe and the US, there are few studies and even fewer have explored the effects over time (Herbers et al., 2012). An earlier concurrent study of reading and factors related to academic achievement has been conducted on the Roma population (Biro, Smederevac, \& Tovilovic, 2009). Results of this study show that socioeconomic background had a strong influence on reading achievement and educational attainment, but this effect was explained by intellectual abilities. This finding was confirmed by another concurrent study that examined national assessments in the third grade in Serbia (Baucal, 2006). A large gap in educational achievements was observed between Roma and non-Roma students, and approximately $50 \%$ of the Roma students did not develop even the most basic literacy skills. Moreover, approximately $40 \%$ of this gap was explained by the lower SES of the Roma children (Baucal, 2006).

In a rare longitudinal study of children in the US who faced poverty, homelessness, and high residential mobility, their reading growth was compared to the growth of the students with a low or moderate SES (Herbers et al., 2012). The study showed that SES predicted achievement beyond the effects of early reading and also moderated later growth in reading achievement from early reading. However, this study did not control for other cognitive or linguistic variables. However, in another US study of children facing severe poverty, results show that later reading skills was to a large extent explained by prior levels of emergent literacy rather than socio-economic background (Hecht \& Greenfield, 2002). Notably, there are also lines of literature that have examined children in poverty in low-income countries. A review of such studies finds that the results partially corroborate the findings from high-income countries and, for instance, also demonstrates that home environments impact literacy development (Nag, Vagh, Dulay, \& Snowling, 2019).

Another important issue when studying the growth rate of reading skills is accounting for bilingualism. Many children in poverty (including Roma) speak two languages and the language spoken at their school is different from their mother tongue. Accounting for bilingualism is important because its effects on the development of reading skills are well-documented but contradictory (for review see MelbyLervåg \& Lervåg, 2014). On one hand, bilingual children seem to have an advantage in phonological skills and decoding (Adesope Lavin, Thompson \& Ungerleider, 2013). On the other hand, while this advantage was observed particularly in studies conducted in Canada, in the studies conducted in the US the opposite was true (Melby-Lervåg \& Lervåg, 2014).

One explanation for the inconsistent patterns is that there seems to be an interaction between decoding skills and SES: Bilingual children with a low SES have been shown to have poorer decoding skills than their monolingual peers, while bilingual children with a middle/high SES were at the same level (Melby-Lervåg \& Lervåg, 2014). However, the meta-analysis indicated that the impact of bilingualism on word decoding is understudied particularly in groups with low SES and more studies are warranted to explain this relationship. The complexity in this relationship is also emphasized in a recent review of studies of children in poverty in low income countries (Nag et al., 2019). This review indicates that many children living in poverty in developing countries use a different language at home than in school. This bilingualism is often considered as a factor that slows down language development, and put constrains on literacy skills (Melby-Lervåg \& Lervåg, 2014). However, the review by Nag and colleagues (2018) finds that this issue is complicated and that how this bilingualism affects literacy development is context-dependent and not a uniform 
constraint. Thus, bilingualism is a potentially important factor and to take this into account, the study will include two Roma samples, one bilingual and one monolingual.

\subsection{The current study}

Although there are a handful of studies concerning children facing severe poverty and also studies focused on the Roma population, they are limited when it comes to the number of predictors, number of participants and number of time points that participants were assessed (Baucal, 2006; Biro, Smederevac, \& Tovilovic, 2009; Herbers et al., 2012). In this study, the effects of SES on the growth of decoding skills will be measured on a large sample of participants in multiple time points while accounting for its main predictors (namely phonological awareness, letter knowledge, RAN and non-verbal abilities) as well as for absenteeism.

Further, to date no study has compared the development of decoding skills of bilingual and monolingual Roma children. Given that the impact from bilingualism on word decoding is understudied in groups with low SES, here the bilingual and monolingual Roma children will be treated in two different groups to elaborate on this issue.

Finally, while most of the previous studies on Roma relied more on group-based assessments and questionnaires related to achievement rather, in this study the participants are assessed individually.

Therefore, this study address the following hypotheses:

- Compared to non-Roma children, the Roma children will have both poorer initial reading skills and a slower reading skill growth.

- There will be small differences in initial levels and growth between monolingual and bilingual Roma children.

- In contrast to the main findings of studies of non-deprived groups, in addition to explaining the initial status, SES will explain reading skill growth.

- School absence will partially mediate the relationship between SES and reading skill growth.

- The growth in early reading will be partially mediated by cognitive variables, such as phonological awareness and rapid automatized naming.

\section{Method}

\subsection{Participants and design}

The participants were children of Roma and non-Roma ethnicity from 21 schools in the northwestern region of Romania. The percentage of the Roma population in the respective communities varies from $1 \%$ to $47 \%$. Parental consent was obtained for five hundred children in first grade (261 boys, age 7 years $S D=0.44$, range $=6-9$ years). Of these participants, one hundred and seventy-one were monolingual Roma (90 boys, $\mathrm{M}$ age $=7.07$ years, $S D=0.48$ ). All monolingual Roma spoke Romanian (the official language of Romania) at home and at school. One hundred and fifty-one participants were bilingual Roma (82 boys, $M$ age $=7.07$ years, $S D=0.48)$. The bilingual Roma spoke mostly Romani as a first language at home (an Indo-Aryan language, highly different from Romanian, which is a Romance language), but Romanian at school. One hundred and seventy-eight participants were monolingual non-Roma ( 89 boys, $M$ age $=6.90$ years, $S D=0.40$ ). The nonRoma spoke Romanian at home and at school.

The design was longitudinal in nature with four measurement points. The data were collected during the following four time points: T1 (October 2014; $N=500$ ), T2 (May 2015; $N=489$ ), T3 (October 2015; $N=464$ ), and T4 (May 2016; $N=466$ ). The sample attrition rate was $2.20 \%$ during the 1 st grade and $7.20 \%$ during the 2 nd grade. Notably, there was also little residential mobility in the sample.

\subsection{Procedures}

The assessment battery was individually administered to the children at the school by trained research assistants with backgrounds in psychology or the educational sciences. The demographic questionnaire was completed by the parents at the school. The demographic data, the linguistic and the cognitive test results were collected at Time 1.

\subsection{Instruments}

Reading skills were assessed according to the number of words and nonwords in a disconnected text that were read correctly in $40 \mathrm{~s}$. This test was developed in Romanian based on the Test of Word Reading Efficiency - Second Edition (TOWRE-2) (see Torgesen, Wagner, \& Rashotte, 2012). The maximum number of points was 56 for both the word and nonword task.

SES was measured by a demographics questionnaire completed by the parents that included the following four scales: family income, mother's education, parents' employment and living conditions. Family income was scored using a 13-point scale ranging from 1 (less than 50 USD/month) to 13 (more than $1000 \mathrm{USD} /$ month). Notably, the net median income in Romania reported by the Labor Department at the beginning of the data collection was approximately $450 \mathrm{USD} / \mathrm{month}$ in 2014 (ranked 9 on our scale). The mother's education level was scored on a 9-point scale with 1 representing persons that had elementary school as the highest level of education and 9 representing persons with a $\mathrm{PhD}$ degree as the highest level of education. The parents' employment was scored on a scale from 0 to 1 , with 0 representing that both parents were unemployed, 0.5 representing that one parent were employed and 1 representing that both parents were employed. The living conditions were scored according to the ratio of the number of people living in the same household to the number of rooms available. The living conditions scores ranged from 0.5 to 10 .

Rapid automatized naming (RAN) included the following two tasks: naming colors (i.e., red, black, brown, green, and yellow) and naming familiar objects (i.e., ball, fish, key, hammer, and pencil). All items were bi-syllabic words. The five items in each task were randomly distributed eight times; thus, the total number of items presented in each task was 40 . Their answers were scored according to the number of seconds required to read each list of items.

Phonological awareness was assessed using the phonological processing subscale of the Developmental NEuroPSYchological Assessment (NEPSY) battery (Korkman, Kirk, \& Kemp, 1998), which has been adapted and validated in a Romanian population (Petra \& Porumb, 2005). These measures include the following two subcomponents: Word Segment Recognition and Phonological Segmentation. The Word Segment Recognition component required the children to identify words from word segments by identifying one of three displayed pictures. The Phonological Segmentation component included two sub-tasks. One task required the children to repeat a word and then to say the word after one sound was deleted, thus making a new word. The other task required the children to say one word and then to substitute one syllable ( $c l$-) with syllable ( $g r$-), thus making a new word. After 5 consecutive scores of 0 , the task was discontinued. The children's answers were scored using a scale from 0 to 36 .

Letter knowledge was measured by asking the children to correctly identify the sound of each of the 28 upper-case letters from the Romanian alphabet. The items of each task were displayed on a separate piece of paper. All letters were displayed in large-sized fonts (48) and were distributed randomly. Each correct answer earned one point, and the children's answers were scored using a scale from 0 to 28 .

Nonverbal IQ was measured using the Raven's colored progressive matrices (Raven, Raven, \& Court, 1991), which have been adapted and validated in a Romanian population. This measure includes 36 items and requires children to identify the missing component that completes a pattern by selecting one of the answers presented in a multiple-choice 
Table 1

Means, standard deviations and reliability of all variables across ethnicity groups and time points.

\begin{tabular}{|c|c|c|c|c|c|c|c|c|c|c|c|}
\hline & & \multicolumn{3}{|c|}{ Bilingual Roma } & \multicolumn{3}{|c|}{ Monolingual Roma } & \multicolumn{3}{|l|}{ Non-Roma } & \multirow{2}{*}{$\begin{array}{l}\text { Group differences in } \\
\text {-means }{ }^{\text {b }}\end{array}$} \\
\hline & & Range & $M(S D)$ & Reliability & Range & $M(S D)$ & Reliability & Range & $M(S D)$ & Reliability & \\
\hline \multirow[t]{4}{*}{ Decoding Words } & $\mathrm{T} 1$ & $0-19$ & $2.70(4.43)$ & $.95^{\mathrm{a}}$ & $0-25$ & $4.50(6.07)$ & $.96^{\mathrm{a}}$ & $0-41$ & $10.17(8.93)$ & $.96^{\mathrm{a}}$ & $\mathrm{BL}<\mathrm{ML}<\mathrm{NR}$ \\
\hline & $\mathrm{T} 2$ & $0-48$ & $\begin{array}{l}11.52 \\
(10.20)\end{array}$ & $.96^{\mathrm{a}}$ & $0-48$ & $\begin{array}{l}13.37 \\
(11.01)\end{array}$ & $.94^{\mathrm{a}}$ & $0-56$ & $\begin{array}{l}22.48 \\
(11.60)\end{array}$ & $.94^{\mathrm{a}}$ & $\mathrm{BL}, \mathrm{ML}<\mathrm{NR}$ \\
\hline & T3 & $0-56$ & $\begin{array}{l}12.66 \\
(12.04)\end{array}$ & $.97^{\mathrm{a}}$ & $0-56$ & $\begin{array}{l}14.92 \\
(12.34)\end{array}$ & $.96^{\mathrm{a}}$ & $0-56$ & $\begin{array}{l}25.50 \\
(13.02)\end{array}$ & $.91^{\mathrm{a}}$ & $\mathrm{BL}<\mathrm{ML}<\mathrm{NR}$ \\
\hline & $\mathrm{T} 4$ & $0-56$ & $\begin{array}{l}19.11 \\
(14.82)\end{array}$ & $.96^{\mathrm{a}}$ & $0-56$ & $\begin{array}{l}23.67 \\
(16.10)\end{array}$ & $.95^{\mathrm{a}}$ & $0-56$ & $\begin{array}{l}35.60 \\
(14.05)\end{array}$ & $.92^{\mathrm{a}}$ & $\mathrm{BL}<\mathrm{ML}<\mathrm{NR}$ \\
\hline \multirow[t]{4}{*}{ Decoding Nonwords } & $\mathrm{T} 1$ & $0-20$ & $2.53(4.45)$ & $.95^{\mathrm{a}}$ & $0-23$ & $3.91(5.35)$ & $.96^{\mathrm{a}}$ & $0-31$ & $8.69(7.40)$ & $.96^{\mathrm{a}}$ & $\mathrm{BL}<\mathrm{ML}<\mathrm{NR}$ \\
\hline & $\mathrm{T} 2$ & $0-37$ & $9.36(8.11)$ & $.96^{\mathrm{a}}$ & $0-35$ & $10.33(7.87)$ & $.94^{\mathrm{a}}$ & $0-48$ & $17.20(8.00)$ & $.94^{\mathrm{a}}$ & $\mathrm{BL}, \mathrm{ML}<\mathrm{NR}$ \\
\hline & $\mathrm{T} 3$ & $0-38$ & $\begin{array}{l}10.35 \\
(10.40)\end{array}$ & $.97^{\mathrm{a}}$ & $0-38$ & $11.64(9.11)$ & $.96^{\mathrm{a}}$ & $0-46$ & $19.27(8.84)$ & $.91^{\mathrm{a}}$ & $\mathrm{BL}, \mathrm{ML}<\mathrm{NR}$ \\
\hline & $\mathrm{T} 4$ & $0-56$ & $\begin{array}{l}15.21 \\
(11.62)\end{array}$ & $.96^{\mathrm{a}}$ & $0-48$ & $\begin{array}{l}17.34 \\
(11.62)\end{array}$ & $.95^{\mathrm{a}}$ & $0-56$ & $\begin{array}{l}27.39 \\
(11.60)\end{array}$ & $.92^{\mathrm{a}}$ & $\mathrm{BL}, \mathrm{ML}<\mathrm{NR}$ \\
\hline Mother's Education & & $1-6$ & $1.77(0.95)$ & & $0-6$ & $1.93(0.97)$ & & $1-7$ & $3.50(1.34)$ & & $\mathrm{BL}, \mathrm{ML}<\mathrm{NR}$ \\
\hline Family Income & & $1-11$ & $4.29(2.62)$ & & $1-12$ & $4.36(2.66)$ & & $1-13$ & $7.00(3.31)$ & & $\mathrm{BL}, \mathrm{ML}<\mathrm{NR}$ \\
\hline People/Room & & $0.75-9.00$ & $3.36(1.99)$ & & $0.50-8.00$ & $3.45(1.78)$ & & $0.50-10.00$ & $2.06(1.19)$ & & $\mathrm{BL}, \mathrm{ML}>\mathrm{NR}$ \\
\hline Parents' Employment & & $0-1$ & $0.26(0.32)$ & & $0-1$ & $0.31(0.36)$ & & $0-1$ & $0.64(0.42)$ & & $\mathrm{BL}, \mathrm{ML}<\mathrm{NR}$ \\
\hline Absence from School & & $0-94$ & $\begin{array}{l}24.108 \\
(18.52)\end{array}$ & & $0-134$ & $\begin{array}{l}27.09 \\
(29.73)\end{array}$ & & $0-53$ & $6.96(9.04)$ & & $\mathrm{BL}, \mathrm{ML}>\mathrm{NR}$ \\
\hline \multicolumn{2}{|l|}{ Phonological Awareness } & $0-22$ & $8.80(4.32)$ & $.81^{\mathrm{b}}$ & $0-22$ & $10.43(4.49)$ & $.82^{\mathrm{b}}$ & $0-32$ & $12.58(5.95)$ & $.88^{\mathrm{b}}$ & $\mathrm{BL}<\mathrm{ML}<\mathrm{NR}$ \\
\hline \multicolumn{2}{|l|}{ Raven } & $1-33$ & $13.56(5.64)$ & $.81^{\mathrm{b}}$ & $1-30$ & $15.80(5.11)$ & $.81^{\mathrm{b}}$ & $4-33$ & $20.27(6.12)$ & $.86^{\mathrm{b}}$ & $\mathrm{BL}<\mathrm{ML}<\mathrm{NR}$ \\
\hline \multicolumn{2}{|l|}{ Letter Knowledge ${ }^{\mathrm{b}}$} & $0-56$ & $\begin{array}{l}10.30 \\
(10.11)\end{array}$ & $.98^{\mathrm{b}}$ & $0-56$ & $\begin{array}{l}14.34 \\
(10.28)\end{array}$ & $.97^{\mathrm{b}}$ & $0-56$ & $22.13(7.95)$ & $.97^{\mathrm{b}}$ & $\mathrm{BL}<\mathrm{ML}<\mathrm{NR}$ \\
\hline \multicolumn{2}{|l|}{ RAN } & $66-263$ & $\begin{array}{l}133.66 \\
(36.67)\end{array}$ & $.56^{\mathrm{c}}$ & $68-262$ & $\begin{array}{l}124.40 \\
(34.10)\end{array}$ & $.58^{\mathrm{c}}$ & $57-213$ & $\begin{array}{l}104.96 \\
(26.85)\end{array}$ & $.71^{\mathrm{c}}$ & $\mathrm{BL}, \mathrm{ML}>\mathrm{NR}$ \\
\hline
\end{tabular}

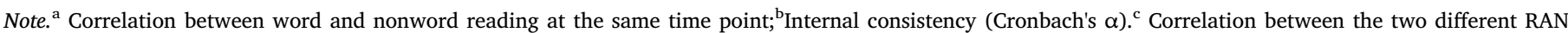

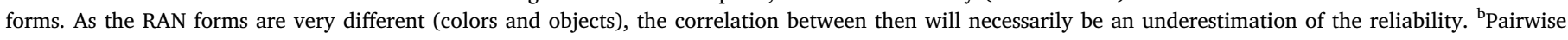
comparisons with least square differences after ANOVA. All $p s<.05$.

A

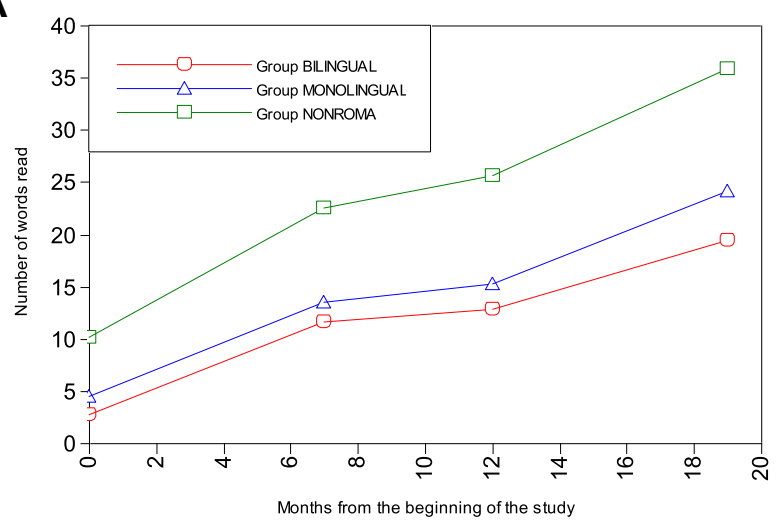

B

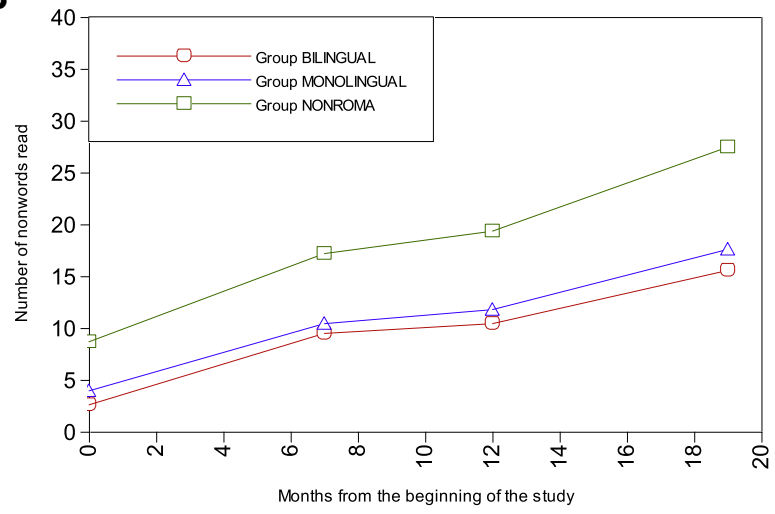

Fig. 1. The average growth of word (a) and nonword (b) reading. format. The items are presented in order of increased difficulty. Each correct answer earned one point, and the children's answers were scored using a scale from 0 to 36 .

School absenteeism was measured by using the data from the official school records. This measure included the sum of daily absences recorded between Time1 and Time 4 .

\section{Results}

The means, standard deviations and reliability of all variables at all time points are shown in Table 1 . The correlations between the variables are shown in Table A1-2 online supplement. As can be seen, the two reading variables (word and nonword reading) are both strongly correlated with each other and are stable over time. All analyses were performed via Mplus 8.0 (Muthén \& Muthén, 1998-2017) using full information maximum likelihood (FIML) with clustered robust (HuberWhite) standard errors to control for dependency on the school level. In some models, there were negative but non-significant residuals from certain reading variables. As these were non-significant, there is statistical support for these residuals being sampling fluctuations, and they were fixed to zero.

\subsection{Growth of reading skills}

To investigate and compare the reading development across the three groups, two growth models was estimated: one model was used to estimate word reading, and the other model was used to estimate nonword reading. The reason for using two separate models instead of one combining word and nonword reading into one factor is that, even if the correlation was very high between word and nonword reading, there was no measurement invariance across time. The two estimated models had an intercept factor that described the initial reading skills status and a slope factor that described the growth from the first time point to the last time point. Because the growth was nonlinear, the analyses freely estimated the factor loadings for the two middle time 
points. As shown in Fig. 1, little development occurred during the five months between Time points 2 and 3, which included a summer vacation. To improve the model fit, the residuals of Times 2 and 3 were allowed to covary. These two time points are close to each other in time (including a summer holiday in between) compared to the other time points; therefore, it is likely that these time points have more commonalities with each other than with Time points 1 and 4 .

The mean of the initial status (intercepts) and the growth rates (slopes) of both word and nonword reading were significantly different from zero with significant variations among the children in all three groups. Wald tests showed that there were significant differences across the groups in both intercepts (word reading: $\chi^{2}(2)=17.610, p<.001$ and nonword reading: $\chi^{2}(2)=21.619, p<.001$ ) and slopes (word reading: $\chi^{2}(2)=30.530, p<.001$ and nonword reading: $\chi^{2}$ $(2)=16.805, p<.001)$. The pairwise comparisons revealed that the two Roma groups had poorer initial reading skills and a slower reading skills growth than the non-Roma group. The two Roma groups did not differ from each other in either the initial status or growth. Table 2 shows the means and standard deviations of the intercept and slopes in addition to the correlations between the intercept and slope for all three groups. As can be seen, the correlations between the intercepts and their corresponding slopes were in general positive, indicating that those who had the best initial reading skills were also those who developed their reading skills faster later on. The models fit the data very well for both word reading $\left(\chi^{2}(14)=23.806, p=.048\right.$, RMSEA $=$ $.065(10 \% \mathrm{CI}=.006-.108), \mathrm{CFI}=.996, \mathrm{TLI}=.995, \mathrm{SRMR}=.038)$ and nonword reading $\left(\chi^{2}(12)=16.824, p=.156\right.$, RMSEA $=.049$ $(10 \% \mathrm{CI}=.000-.100), \mathrm{CFI}=.997, \mathrm{TLI}=.995, \mathrm{SRMR}=.040)$.

\subsection{The role of SES in reading growth}

In order to test if SES is related to the growth of reading skills, two models was estimated (one model for word reading and another model for nonword reading) in which the initial status and growth of the two reading variables were regressed on a formative SES construct (see Fig. 2a and b). This construct can be seen as a weighted sum of mother's education level, family income, housing conditions and employment status. Because the regression weights of this SES construct did not vary as a function of the groups (word reading model: $\chi^{2}(6)=3.274$, $p<.774$, and nonword reading model: $\chi^{2}(6)=3.756, p=.723$ ), the weights were fixed to be equal for all three groups. Furthermore, because the paths from SES to initial status and growth did not differ across the groups (word reading model initial status: $\chi^{2}(2)=2.052$, $p=.358$ and growth: $\chi^{2}(2)=1.266, p=.531$; nonword reading model initial status: $\chi^{2}(2)=1.884, p=.390$ and growth: $\chi^{2}$ $(2)=2.019, p=.364$ ), these paths were fixed to be equal as well. In addition, reading growth were regressed on initial status to avoid initial status to confound the relationship between SES and reading growth. Fig. 2a and $b$ shows that all the four indicators of SES predicted the SES construct, with housing condition being the strongest. In these models, it is the unstandardized coefficients that are fixed to be equal and the reason for why the standardized values differ is that the variances of the variables differ across groups. In addition, both the initial status and the reading skills growth were predicted by the SES. The models fit the data very well for both word reading $\left(\chi^{2}(57)=83.211, p=.013\right.$, RMSEA $=0.053(10 \%$ CI $=0.025-.076), C F I=0.989, \quad$ TLI $=0.987$, SRMR $=0.058)$ and for nonword reading, $\left(\chi^{2}(54)=81.668, p=.010\right.$, RMSEA $=0.055 \quad(10 \% \quad \mathrm{CI}=0.028-.79), \quad$ CFI $=0.985, \quad$ TLI $=0.982$, SRMR $=0.047$.

To further explore potential group differences in the development of decoding skills across three groups we tested if there were significant differences in the conditional means of both the initial status and growth rate after controlling for SES. Wald tests showed that there were still significant differences between the groups for both word: $\chi^{2}$ $(2)=9.679, p=.008$ (conditional mean $=2.666,4.358$ and 7.409 for the bilingual Roma, monolingual Roma and non-Roma groups 
A

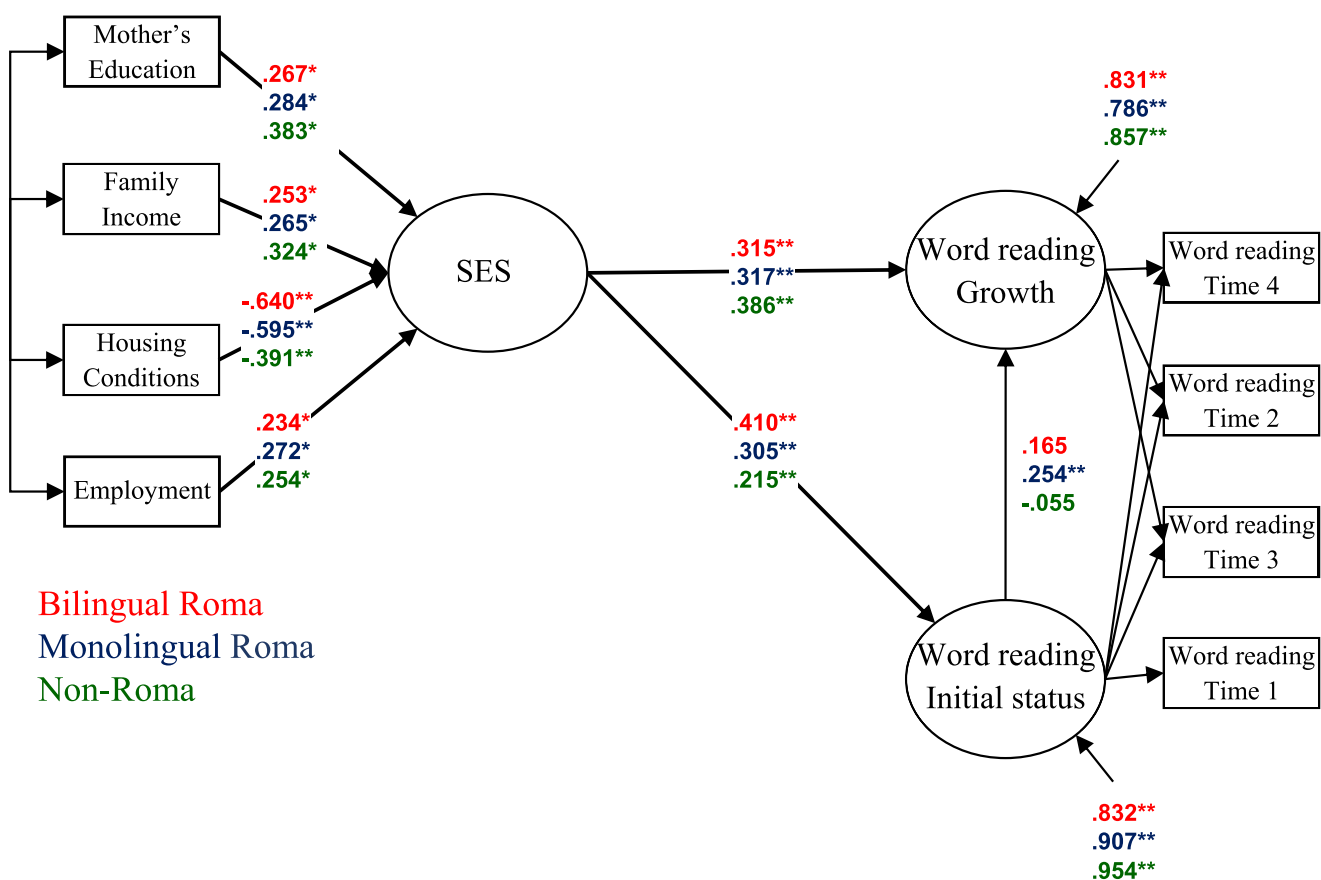

B

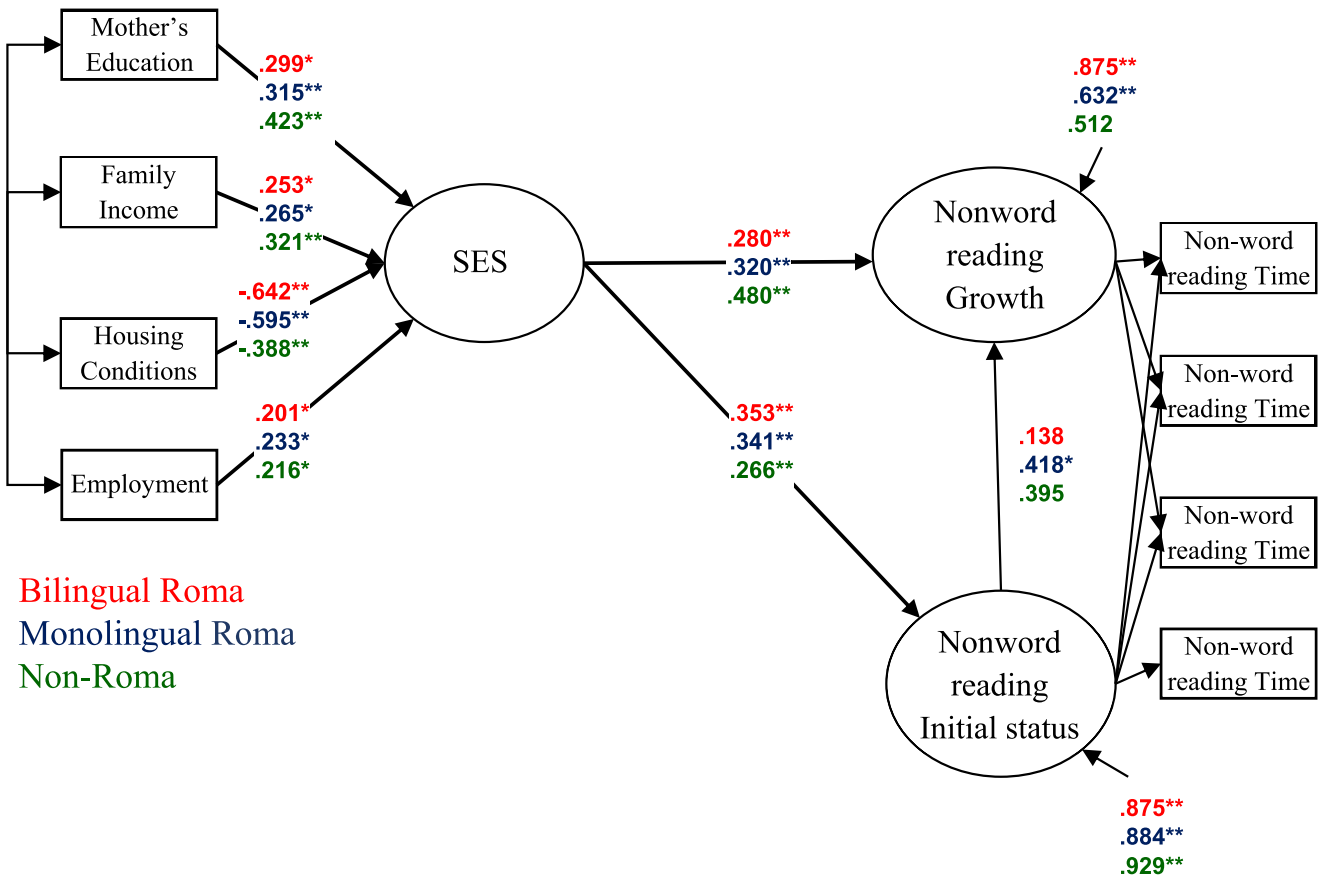

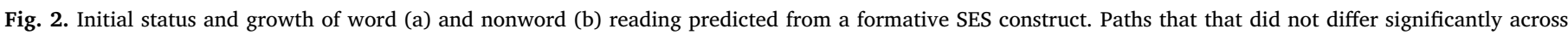
groups are fixed to be equal across groups and drawn in bold. All coefficients are standardized.

respectively) and for nonwords $\chi^{2}(2)=8.964, p=.011$ (conditional mean $=2.457,3.740$ and 6.105 for the bilingual Roma, monolingual Roma and non-Roma groups respectively). Pairwise comparisons revealed that the conditional mean in the bilingual group was smaller than in the monolingual group which was again smaller that the nonRoma group for word reading. For nonword reading, there were no significant differences in the conditional initial status means between the two Roma groups but the means of these two groups were smaller than the mean of the non-Roma group. For the growth of decoding skills, the original differences between the groups disappeared when SES was controlled. This was confirmed by a Wald test for word $\chi^{2}$
(2) $=5.340, p=.069$ (conditional mean $=0.811, .867$ and 1.071 for the bilingual Roma, monolingual Roma and non-Roma groups respectively) and for nonword $\chi^{2}(2)=0.841, p=.657$ (conditional mean $=0.640, .554$ and .605 for the bilingual Roma, monolingual Roma and non-Roma groups respectively).

3.3. The role of school absence and cognitive and linguistic variables as mediators of SES and reading growth

To determine whether absence from school and the cognitive and linguistic variables (i.e., letter knowledge, RAN, phoneme awareness 
A

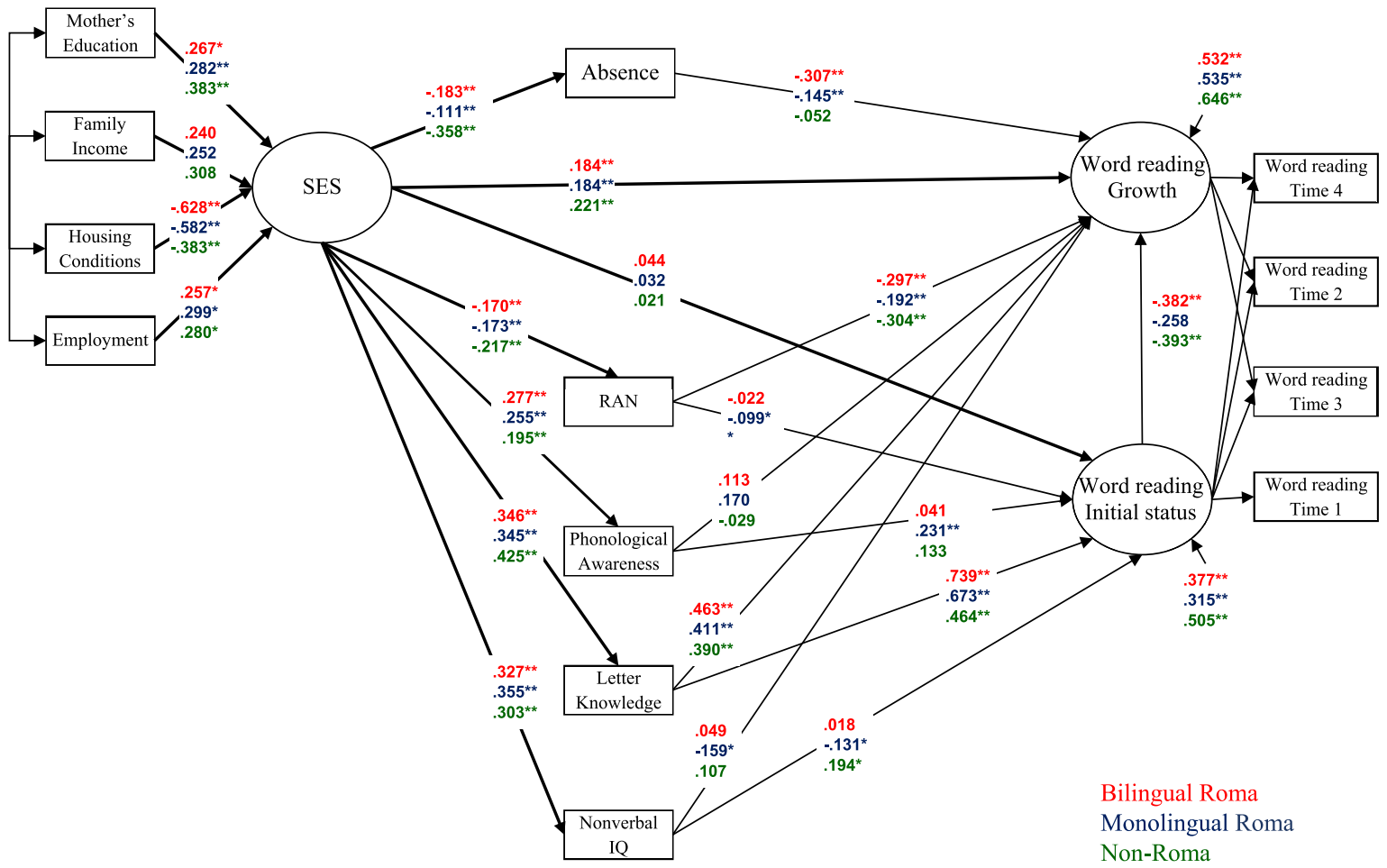

B

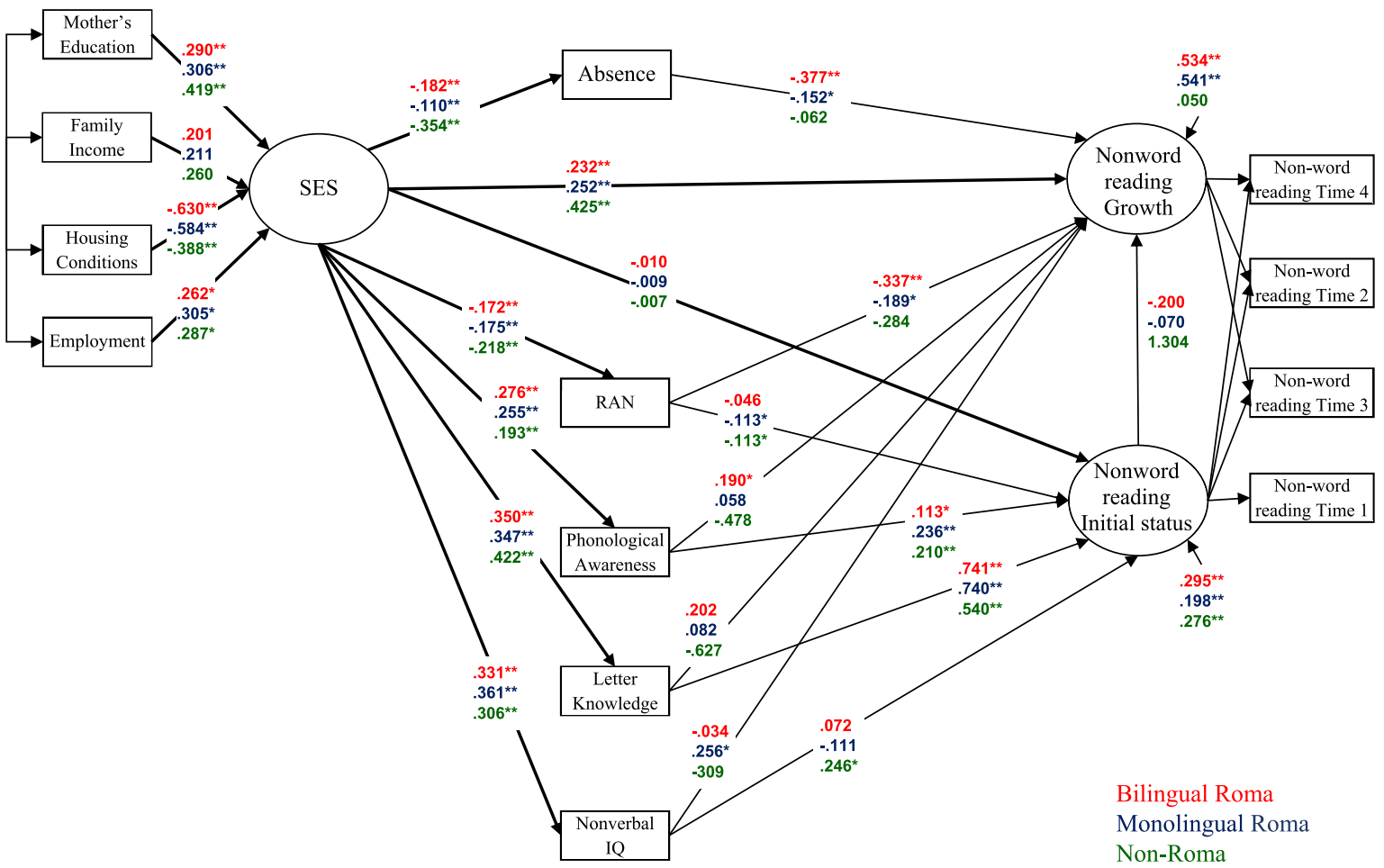

Fig. 3. Multiple mediation models were the effect of SES on word (a) and nonword (b) reading initial status and growth is partly mediated through absence and the cognitive and linguistic variables. Paths that that did not differ significantly across groups are fixed to be equal across groups and drawn in bold. All coefficients are standardized. 
and nonverbal abilities) mediated the relationship between SES and reading skills growth, the multiple mediation models as shown in Fig. 3 was estimated.

In these models, the invariance was tested for various paths across the three groups in a hierarchical fashion: 1) the path from SES to school absence, 2) the path from SES to the cognitive/linguistic variables, 3) the direct paths from SES to the initial status, 4) the direct paths from SES to the reading skills growth, 5) the path from school absence to reading growth, 6) the path from the cognitive/linguistic variables to the initial status of reading skills and 7) the path from the cognitive/linguistic variables to the reading skills growth. Table B in online supplemental show the results of these invariance tests. All paths that did not differ across the groups were fixed to be equal in the final model, which is shown in Fig. 3a and b for the word and nonword models respectively. As it is the unstandardized coefficients that are fixed to be equal, the reason for why the standardized values differ is that the variances of the variables differ across groups.

The direct paths from SES to the initial status of reading skills were no longer significant, indicating that the relationship between SES and beginning reading skills was fully mediated through the cognitive and linguistic variables. These mediated standardized paths (total indirect effects of SES on initial status through the cognitive/linguistic variables) were $.277, .262$ and .304 (all significant, $p<.001$ ) for the bilingual Roma, monolingual Roma and non-Roma children respectively for word reading and .322, .296 and .369 (all significant, $p<.001$ ) for the bilingual Roma, monolingual Roma and non-Roma children respectively for nonword reading. For details, see Tables C and D online supplemental material for word and nonword reading, respectively. A total of $62.3 \%, 68.5 \%$ and $49.5 \%$ of the variance in the word reading initial status was explained in the bilingual Roma, the monolingual Roma and the non-Roma group respectively and total of $72.1 \%, 80.2 \%$ and $72.4 \%$ of the variance in the nonword reading initial status was explained in the bilingual Roma, the monolingual Roma and the nonRoma group respectively.

However, the direct paths from SES to the reading skills growth remained significant for both word and nonword reading, ranging from.184 to .425. The total mediated standardized effects from SES on word reading growth was .187, .215 and .150 (all significant, $p<.001$ ) for the bilingual Roma, monolingual Roma and non-Roma children respectively for word reading and .176 $(p=.005), .206$ $(p<.001)$ and $.105(p=.273)$ for the bilingual Roma, monolingual Roma and non-Roma children respectively for nonword reading. Furthermore, the relationship between SES and reading growth was partly mediated by school absences in both Roma groups in the word reading model (Indirect effects: Bilingual Roma: .056, $p=.005$; Monolingual Roma: .016, $p=.036$; non-Roma: .019, $p=.198$ ) but only for the bilingual Roma group in the nonword reading model (Indirect effects: Bilingual Roma: .069, $p=.003$; Monolingual Roma: .017, $p=.119$; non-Roma: .022, $p=.525$ ). The cognitive and linguistic variables mediated the relationship between SES and reading growth in all groups in the word reading model (Indirect effects: Bilingual Roma: $.147, p=.004$; Monolingual Roma: .207, $p<.001$; non-Roma: .139, $p<.001$ ), but only for the two Roma groups in the nonword reading model (Indirect effects: Bilingual Roma: .108, $p=.024$; Monolingual Roma: .186, $p<.001$; non-Roma: .091, $p=.102$ ). For details, see Tables $\mathrm{E}$ and $\mathrm{F}$ online supplemental material for word and nonword reading, respectively. A total of $46.8 \%, 46.5 \%$ and $35.4 \%$ of the variance in the word reading growth was explained in the bilingual Roma, the monolingual Roma and the non-Roma group respectively and total of $46.6 \%, 45.9 \%$ and $95 \%$ of the variance in the nonword reading growth was explained in the bilingual Roma, the monolingual Roma and the non-Roma group respectively. These two final mediation models fit the data very well (word reading: $\chi^{2}(151)=211.353$, $p=.001, \quad$ RMSEA $=0.049 \quad(10 \% \quad \mathrm{CI}=0.032-.064), \quad$ CFI $=0.981$, $\mathrm{TLI}=0.973, \quad$ SRMR $=0.057$ and nonword reading $\chi^{2}$ $(150)=222.299, p<.001$, RMSEA $=0.054(10 \% \mathrm{CI}=0.038-.068)$,
$\mathrm{CFI}=0.975, \mathrm{TLI}=0.964, \mathrm{SRMR}=0.057)$

\section{Discussion}

This longitudinal comparison of reading development in bilingual and monolingual Roma children, compared with children without this minority background, had several important findings: Roma children had both poorer reading skills at the beginning of the study and a slower subsequent development of their reading skills. There were no differences in reading skills between the monolingual and bilingual Roma groups. Furthermore, SES explained a considerable amount of the variance in both the initial status and the reading skills growth. The effect of SES on the initial reading status was fully mediated by the four cognitive and linguistic variables (i.e., RAN, phoneme awareness, letter knowledge and nonverbal abilities). The direct effect of SES on the actual reading skills growth was significant, but there was a partial mediation by school absence in the Roma children and by the four cognitive and linguistic variables in all three groups.

\subsection{Differences between the groups in initial status and growth}

In line with the first hypothesis results showed that in the beginning of formal reading instruction, Roma children start out with poorer reading skills than their non-Roma peers. This is in line with prior crosssectional studies of Roma children that also show that they have poorer reading skills than non-Roma children and confirm an academic achievement gap (due also to poor basic literacy) between the Roma ethnic children and their non-Roma peers (Biro et. Al., 2009; Baucal, 2006). Given that neither of these previous studies were longitudinal in nature, the present study extends the findings of those by showing that the Roma children had a slower growth in reading skills than the monolingual children.

Further, the findings also suggested that all differences in the growth rates between groups can be attributed to differences in SES. However, this was not the case for initial status as there were still differences in the means after controlling for SES. Thus, a main finding in this study is that the Roma children not only are behind their nonRoma peers initially, but also simply learn to read at a slower pace than their peers with higher SES and Romanian schools are not able to compensate for differences in SES when it comes to improving reading. These findings are consistent with two other studies that also identified slower growth rates in children with a low SES (Hecht et al., 2000; Herbers et al., 2012).

The results also showed that some associations between SES and reading growth were mediated by school absence, in both Roma groups but not among the non-Roma children. This finding can be related to the fact that very little absenteeism were found among the non-Roma children compared to the Roma children. Many studies have shown a relationship between school absence, SES and reading skills (Buckingham, Beaman, \& Wheldall, 2014). However, unlike previous studies, here, it was demonstrated that school absence affects reading skills growth.

As for bilingualism, there was no differences between monolingual and bilingual Roma children in decoding at initial status. This corresponds with prior meta-analysis showing that monolingual and bilingual children have comparable decoding skills. Notably, even if bilinguals and monolinguals overall tend to be on a similar level on decoding and phonological awareness, a meta-analysis showed that low SES is associated with larger group differences also in decoding in favor of monolinguals (Melby-Lervåg \& Lervåg, 2014). This overall finding from the meta-analysis was however not supported in the current study. This is most likely since the differences in SES between the monolingual and bilingual Roma children were small, and therefore not likely to create a difference between these two Roma groups here. 


\subsection{The relationships between SES, cognitive/linguistic predictors and reading development}

The results showed that SES predicted the initial reading skills and that this prediction was fully mediated by the four cognitive and linguistic variables. These results are consistent with earlier studies (Bowey, 1995; Hecht et al., 2000; Raz \& Bryant, 1990). The explanations for this are probably multifaceted and complex. However, one explanations that is often put forward is that parents with low SES might be less interested in books, reading and education than high SES families (Crosnoe, Leventhal, Wirth, Pierce, \& Pianta, 2010; Hoff, 2006). This might lead to less focus on and knowledge of letters and poorer phonological skills when they begin school than children with a high SES (Bracken \& Fischel, 2008; Buckingham et al., 2014; Hoff, 2006). This is lent support from the fact that the mothers' education level was a consistent and significant contributor to the SES construct in all models and that letter knowledge was clearly the strongest mediator of the four cognitive and linguistic variables. Notably, other environmental factors than home literacy could also play an important role. One such factor is poor nutrition in low SES families (Darmon \& Drewnowski, 2015; Wang \& Beydoun, 2007). Since poor nutrition is associated with poor neural and cognitive development (e.g., Rosales, Reznick \& Zeisel, 2009), this might have a direct effect on the cognitive and linguistic mediators and, thus, an indirect effect on reading skills.

It should also be mentioned that the results in this study also might be, at least to some extent, related to genetics and gene-environment interactions. Twin studies have shown that both the cognitive mediators and reading skills have a genetic component (Christopher et al., 2015). In addition, some (e.g., Tucker-Drob \& Bates, 2016), but not all (e.g., Grasby, Coventry, Byrne, \& Olson, 2017), studies found a gene $\times$ SES interaction in regards to cognitive skills and school achievement, suggesting that genetics may be a stronger predictor of cognitive skills and school achievement in high SES children than in low-SES children. Thus, genetic influences might be less apparent in Roma children due to their general low SES status. This might lead to that the Roma children are not able to exploit their genetic potential in developing the cognitive precursors for reading, and this in turn have a negative impact on their reading development.

Notably, this study is unique in showing that SES might have a direct influence beyond the indirect paths through school absence and the cognitive and linguistic variables. There might be several explanations for this phenomenon. For instance, as mentioned mothers education level is associated with a slower development of children's literacy skills, probably because of a combination of genetic factors and home literacy environment (Dearing, Kreider, Simpkins, \& Weiss, 2006; Hoff, 2006; Puglisi, Hamilton, Hulme, \& Snowling, 2017). In addition, housing conditions were a strong and consistent contributor to the SES construct. Completing homework may be difficult when there are several people living in the same room in the household.

The direct effect from SES beyond the effects of the cognitive and linguistic factors thought to underlie reading development contrasts to some extent the main conclusion in a review of the mechanisms underlying poor reading in poor children, which stated that SES is primarily a proxy for other variables that are more directly salient factors (Buckingham et al., 2013). This lack of direct association in former studies might be attributed to the restricted SES range used in several of these studies, while in the current study the SES range is substantial (Fundamental Rights Agency, 2016). Thus, the cognitive and linguistic variables only seem to partly mediate the relationship between SES and the actual growth of reading skills. The finding that SES is associated with the growth of reading skills tells us that the low SES children do not only have a disadvantage when they start school but are also disadvantaged during school when initial skill levels have been controlled for.

\subsection{Implications and future directions}

This study provides further evidence that SES plays an important role in children's development of reading skills, regardless of their ethnicity. Altogether, this study provides strong evidence that the mechanisms related to SES are fundamental and not only influence the affected children's reading skills level at the start of school but also place constraints on their further literacy development. Further, SES also significantly predicted growth even after accounting for the main cognitive and linguistic predictors of reading skills. Thus, educational intervention needs to focus not only on reading instruction, but also on developing family-school collaborative educational programs that would assist parents on how to improve the home literacy environment (Reynolds et al., 2017). A non-supportive home environment is persistent, and instructional activities conducted at school can only partially compensate for the disadvantages of a low SES (Hoff, 2006).

In addition to their practical value, the findings from this study clearly provide directions for future research. First, more studies including children with severely disadvantaged backgrounds who live in poverty should be conducted since these children are rarely included in research, and studies of children with more moderately disadvantaged backgrounds may provide differing results (Henrich et al., 2010). Second, future studies that investigate the role of SES on reading development should also consider increasing the variance of SES even more by including students from the higher of SES spectrum as well. The current study included children from communities where Roma children could be recruited and these were low to moderate SES communities only. The increased variance that would have been a result of including children from higher SES communities might lead to more pronounced results in the non-Roma group. In addition, comparing the findings from children coming from low to moderate SES communities with children coming from higher SES non-Roma communities could be interesting in itself. Also, as the Fundamental Rights Agency (2016) report shows, there is a large difference in the standard of living for the Roma group between different countries. Thus, there is also a need for studies of the Roma group in other countries in Europe.

Furthermore, this study indicates that intervention studies are highly needed for this group. However, not many well-controlled studies have examined the effects from using broader interventions that in addition to high quality educational instruction also include socioeconomic elements (behavioral/social, family, and health), support indicating that such broader interventions may offer a promising path (Dearing, Walsh et al., 2016). To identify effective elements in such interventions it is also a need for studies that include variables such as nutrition and health, and also behavioral genetic studies that can examine genetic contribution and gene-environment interaction. Thus, interventions targeting broader aspects of these children's lives can potentially be effective, and in the future, more studies are needed to further examine causes and based on this develop well-targeted interventions.

\section{Author note}

No conflicts of interest.

\section{Acknowledgements}

EEA grants/Norway Grants under the program "Research within priority sectors" (15 SEE/30.06.2014).

\section{Appendix A. Supplementary data}

Supplementary data to this article can be found online at https:// doi.org/10.1016/j.learninstruc.2019.101218. 


\section{References}

Adesope, O. O., Lavin, T., Thompson, T., \& Ungerleider, C. (2010). A systematic review and meta-analysis of the cognitive correlates of bilingualism. Review of Educational Research, 80(2), 207-245. https://doi.org/10.3102/0034654310368803.

Baucal, A. D. (2006). Development of mathematical and language literacy among Roma students. Psihologija, 39(2), 207-227. https://doi.org/10.2298/PSI0602207B.

Biro, M., Smederevac, S., \& Tovilović, S. (2009). Socioeconomic and cultural factors of low scholastic achievement of Roma children. Psihologija, 42(3), 273-288. https:// doi.org/10.2298/PSI0903273B.

Bowey, J. A. (1995). Socioeconomic status differences in preschool phonological sensitivity and first-grade reading achievement. Journal of Educational Psychology, 87, 476-487. https://doi.org/10.1037/0022-0663.87.3.476.

Bracken, S. S., \& Fischel, J. E. (2008). Family reading behavior and early literacy skills in preschool children from low-income backgrounds. Early Education \& Development 19(1), 45-67. https://doi.org/10.1080/10409280701838835.

Brïgoemann, C. (2012). Roma education in comparative perspective. Analysis of the UNDP/world bank/EC regional roma survey 2011. Roma inclusion working papers. Bratislava: United Nations Development Programme.

Buckingham, J., Beaman, R., \& Wheldall, K. (2014). Why poor children are more likely to become poor readers: The early years. Educational Review, 66(4), 428-446. https:// doi.org/10.1080/00131911.2013.795129.

Buckingham, J., Wheldall, K., \& Beaman-Wheldall, R. (2013). Why poor children are more likely to become poor readers: The school years. Australian Journal of Education, 57(3), 190-213. https://doi.org/10.1177/0004944113495500.

Caravolas, M., Lervåg, A., Defior, S., Seidlová Málková, G., \& Hulme, C. (2013). Different patterns, but equivalent predictors, of growth in reading in consistent and inconsistent orthographies. Psychological Science, 24(8), 1398-1407. https://doi.org/10. 1177/0956797612473122.

Christopher, M. E., Hulslander, J., Byrne, B., Samuelsson, S., Keenan, J. M., Pennington, B.,., \& Olson, R. K. (2015). Genetic and environmental etiologies of the longitudinal relations between prereading skills and reading. Child Development, 86(2), 342-361. https://doi.org/10.1111/cdev.12295.

Crosnoe, R., Leventhal, T., Wirth, R. J., Pierce, K. M., \& Pianta, R. C. (2010). Family socioeconomic status and consistent environmental stimulation in early childhood. Child Development, 81(3), 972-987. https://doi.org/10.1111/j.1467-8624.2010. 01446.x.

Darmon, N., \& Drewnowski, A. (2015). Contribution of food prices and diet cost to socioeconomic disparities in diet quality and health: A systematic review and analysis. Nutrition Reviews, 73(10), 643-660. https://doi.org/10.1093/nutrit/nuv027.

Dearing, E., Kreider, H., Simpkins, S., \& Weiss, H. B. (2006). Family involvement in school and low-income children's literacy: Longitudinal associations between and within families. Journal of Educational Psychology, 98(4), 653.

Dearing, E., Walsh, M. E., Sibley, E., Lee-St John, T., Foley, C., \& Raczek, A. E. (2016). Can community and school-based supports improve the achievement of first generation immigrant children attending high-poverty schools? Child Development, 87(3), 883-897.

Fundamental Rights Agency (2016). Second European Union minorities and discrimination survey | roma - selected findings. Retrieved from http://fra.europa.eu/en/ publication/2016/eumidis-ii-roma-selected-findings.

Gottfried, M. A. (2010). Evaluating the relationship between student attendance and achievement in urban elementary and middle schools: An instrumental variables approach. American Educational Research Journal, 47(2), 434-465. https://doi.org/ 10.3102/0002831209350494.

Grasby, K. L., Coventry, W. L., Byrne, B., \& Olson, R. K. (2017). Little evidence that socioeconomic status modifies heritability of literacy and numeracy in Australia. Child Development, Early View. https://doi.org/10.1111/cdev.12920.

Grusky, D. (2001). Social stratification: Class, race, and gender in sociological perspective. Boulder, CO: Westview Press.

Hart, B., \& Risley, T. R. (1995). Meaningful differences in the everyday experience of young American children. Baltimore, MD, US: Paul H. Brookes Publishing.

Hecht, S. A., Burgess, S. R., Torgesen, J. K., Wagner, R. K., \& Rashotte, C. A. (2000). Explaining social class differences in growth of reading skills from beginning kindergarten through fourth-grade: The role of phonological awareness, rate of access and print knowledge. Reading and Writing: An Interdisciplinary Journal, 12, 99-127. https://doi.org/10.1023/A:1008033824385.

Hecht, S. A., \& Greenfield, D. B. (2002). Explaining the predictive accuracy of teacher judgments of their students' reading achievement: The role of gender, classroom behavior, and emergent literacy skills in a longitudinal sample of children exposed to poverty. Reading and Writing, 15(7-8), 789-809.

Henrich, J., Heine, S. J., \& Norenzayan, A. (2010). Most people are not WEIRD. Nature, 466(7302), 29. https://doi.org/10.1038/466029a.

Herbers, J. E., Cutuli, J. J., Supkoff, L. M., Heistad, D., Chan, C., Hinz, E., et al. (2012).
Early reading skills and academic achievement trajectories of students facing poverty, homelessness, and high residential mobility. Educational Researcher, 41(9), 366-374. https://doi.org/10.3102/0013189X12445320.

Hoff, E. (2006). How social contexts support and shape language development. Developmental Review, 26, 55-88. https://doi.org/10.1016/j.dr.2005.11.002.

Kieffer, M. J. (2012). Before and after third grade: Longitudinal evidence for the shifting role of socioeconomic status in reading growth. Reading and Writing, 25, 1725-1746.

Korkman, M., Kirk, U., \& Kemp, S. (1998). NEPSY: A developmental neuropsychological assessment. San Antonio, TX: The Psychological Corporation.

Kosko, S. J. (2012). Educational attainment and school-to-work conversion of roma in Romania: Adapting to feasible means or ends? Journal of Human Development and Capabilities, 13(3), 415-450. https://doi.org/10.2304/eerj.2014.13.3.282.

Lervåg, A., Bråten, I., \& Hulme, C. (2009). The cognitive and linguistic foundations of early reading development: A Norwegian latent variable longitudinal study. Developmental Psychology, 45(3), 764. https://doi.org/10.1037/a0014132.

Lervåg, A., \& Hulme, C. (2009). Rapid automatized naming (RAN) taps a mechanism that places constraints on the development of early reading fluency. Psychological Science, 20(8), 1040-1048. https://doi.org/10.1111/j.1467-9280.2009.02405.x.

Melby-Lervåg, M., \& Lervåg, A. (2014). Reading comprehension and its underlying components in second-language learners: A meta-analysis of studies comparing firstand second-language learners. Psychological Bulletin, 140(2), 409-433. https://doi. org/10.1037/a0033890.

Morrisey, T. W., Hutchinson, L., \& Winsler, A. (2014). Family income, school attendance and academic achievement in elementary school. Developmental Psychology, 50(3), 741-753. https://doi.org/10.1037/a0033848.

Muthén, L. K., \& Muthén, B. O. (1998-2017). Mplus Statistical analysis with latent variables. User's Guide (8th ed.). Los Angeles, CA: Muthén \& Muthén.

Nag, S., Vagh, S. B., Dulay, K. M., \& Snowling, M. J. (2019). Home literacy, school Language and children literacy attainments: A systematic review of evidence from low- and middle-income countries. The Review of Education, 7(1), 91-150. https:// doi.org/10.1002/rev3.3130.

Pan, B. A., Rowe, M. L., Singer, J. D., \& Snow, C. E. (2005). Maternal correlates of growth in toddler vocabulary production in low-income families. Child Development, 76(4), 763-782. https://doi.org/10.1111/1467-8624.00498-i1.

Petra, L., \& Porumb, M. (2005). Translation and adaptation of "administering NEPSY: A developmental neuropsychological assessment", subtest administration. Cluj-Napoca: ASCR.

Puglisi, M., Hamilton, L., Hulme, C., \& Snowling, M. (2017). The home literacy environment is a correlate, but perhaps not a cause, of variations in children's language and literacy development. Scientific Studies of Reading, 21(6), 498-514. https://doi. org /10.1080/10888438.2017.1346660.

Rat, C. (2005). Romanian roma, state transfers, and poverty a study of relative disadvantage. International Journal of Sociology, 35(3), 85-116. https://doi.org/10. 1080/00207659.2005.11043152.

Raven, J., Raven, J. C., \& Court, J. H. (1991). Manual for Raven's progressive matrices and vocabulary scales. Section 1 general overview. Oxford: Oxford Psychologists Press.

Raz, I. S., \& Bryant, P. E. (1990). Social background, phonological awareness, and children's reading. British Journal of Developmental Psychology, 8, 209-225. https://doi. org/10.1111/j.2044-835X.1990.tb00837.x.

Ready, D. D. (2010). Socioeconomic disadvantage, school attendance, and early cognitive development: The differential effects of school exposure. Sociology of Education, 83(4), 271-286. https://doi.org/10.1177/0038040710383520.

Reynolds, A. J., Hayakama, M., Ou, S. R., Mondi, C. F., Englund, M. M., Candee, A. J., et al. (2017). Scaling and sustaining effective early childhood programs through school-family-university collaboration. Child Development, 88(5), 1453-1465. https://doi.org/10.1111/cdev.12901.

Rosales, F. J., Reznick, J. S., \& ZeiselS, H. (2009). Understanding the role of nutrition in the brain and behavioral development of toddlers and preschool children: Identifying and addressing methodological barriers. Nutritional Neuroscience, 12, 190-202. https://doi.org/10.1179/147683009X423454.

Sirin, S. R. (2005). Socioeconomic status and academic achievement: A meta-analytic review of research. Review of Educational Research, 75(3), 417-453. https://doi.org/ 10.3102/00346543075003417.

Torgesen, J. K., Wagner, R. K., \& Rashotte, C. A. (2012). TOWRE-2 examiner's manual Austin, TX: Pro-ed.

Tucker-Drob, E. M., \& Bates, T. C. (2016). Large cross-national differences in gene x socioeconomic status interaction on intelligence. Psychological Science, 27, 138-139. https://doi.org/10.1177/0956797615612727.

Wang, Y., \& Beydoun, M. A. (2007). The obesity epidemic in the United States-gender, age, socioeconomic, racial/ethnic, and geographic characteristics: A systematic review and meta-regression analysis. Epidemiologic Reviews, 29(1), 6-28. https://doi. org/10.1093/epirev/mxm007. 